\title{
Neonatal Sepsis - A Study of Predisposing Factors and Causative Organisms
}

\author{
Sharma $\mathrm{A}^{1}$, Mathur $\mathrm{P}^{2}$, Sharma $\mathrm{J} \mathrm{N}^{3}$, Gupta $\mathrm{M}^{4}$, Agarwal A ${ }^{5 *}$

\begin{abstract}
${ }^{1}$ Resident, Department of Pediatrics, Sawai Man Singh Medical College and Attached group of hospitals, Jaipur, India
${ }^{2}$ Associate Professor, Department of Pediatrics, Sawai Man Singh Medical College and Attached group of hospitals, Jaipur, India

${ }^{3}$ Senior Professor, Department of Pediatrics, Sawai Man Singh Medical College and Attached group of hospitals, Jaipur, India

${ }^{4}$ Senior Resident, Department of Microbiology, Sawai Man Singh Medical College and Attached group of hospitals, Jaipur, India

${ }^{5}$ Intern, Department of Pediatrics, Sawai Man Singh Medical College and Attached group of hospitals, Jaipur, India
\end{abstract}

DOI: $10.36347 /$ sjams.2020.v08i10.010

| Received: 23.09.2020 | Accepted: 08.10.2020 | Published: 11.10.2020

*Corresponding author: Dr. Ansh Agarwal

\section{Abstract}

Neonatal sepsis is the most common cause of neonatal mortality and morbidity. Studies have recorded an incidence of neonatal sepsis, varying between 11 and 24.5 per 1000 live births. It is responsible for about 30-50\% of the neonatal deaths. Depending on the onset of symptoms, it can be classified into early onset sepsis within $72 \mathrm{~h}$ of life and late onset sepsis usually after $72 \mathrm{~h}$ of life. It has been one of the major diagnostic problems for physicians due to nonspecific symptoms and the absence of a reliable Para clinical marker. The common risk factors for neonatal sepsis include an Apgar score 6 at 5 minutes, prolonged rupture of membranes, placental inflammation, and clinical amnionitis (maternal fever, fetal tachycardia, and amniotic or gastric fluid leukocytes or bacteria), prematurity and very low birth weight, central vascular catheterization, parenteral nutrition, use of broad spectrum antibiotics, H2 blockers and corticosteroids, endotracheal intubation, and prolonged hospital stay. Early signs of sepsis are nonspecific and may present with episodes of fever, respiratory distress, diarrhea, low blood sugar level, decreased movements, decreased suckling, seizures, bradycardia, swollen belly area, vomiting, jaundice or rash. A heart rate above 160 can also be an indicator of sepsis, this tachycardia can present up to 24 hours before the onset of other signs. Culturing for microorganisms from a sample of CSF, blood or urine, is the gold standard test for definitive diagnosis of neonatal sepsis. Widespread infection despite negative culture is common. In addition to fluid resuscitation and supportive care, a common antibiotic regimen in infants with suspected sepsis is beta-lactam antibiotic in combination with an aminoglycoside or a third generation cephalosporin and organism specific antibiotics. Granulocyte-macrophage colony stimulating factor is sometimes used in neonatal sepsis to correct neutropenia if present but it has no effect on reducing sepsis.

Keywords: Neonatal sepsis, Amnionitis, Low birth weight, APGAR score.

Copyright $\odot 2020$ The Author(s): This is an open-access article distributed under the terms of the Creative Commons Attribution 4.0 International License (CC BY-NC 4.0) which permits unrestricted use, distribution, and reproduction in any medium for non-commercial use provided the original author and source are credited.

\section{INTRODUCTION}

Neonatal sepsis is defined as a disseminated disease with positive blood culture during the first month of life and encompasses various systemic infections of the newborn. It is more common in developing countries compared to developed countries. Neonatal sepsis is the most common cause of neonatal mortality and morbidity. Studies have recorded an incidence of neonatal sepsis, varying between 11 and 24.5 per 1000 live births. It is responsible for about 30 $50 \%$ of the neonatal deaths [1]. Depending on the onset of symptoms, it can be classified into early onset sepsis within $72 \mathrm{~h}$ of life and late onset sepsis usually after 72 $\mathrm{h}$ of life. Knowledge about potential risk factors would help in the early diagnosis of sepsis. Early signs of sepsis are non-specific and subtle. It has been one of the major diagnostic problems for physicians due to the non-specificity of its symptoms and the absence of a reliable Para clinical marker [2]. Advances in neonatal management have led to considerable improvement in newborn survival. However, early ( $<72$ hours) and late (>72 hours) onset systemic infections, both bacterial and fungal remain a devastating complication and an important cause of morbidity in these babies [3]. The objective of this study is to identify risk factors and different infections causing sepsis in neonates depending on their birth weight and gestational age.

\section{ОВJECTIVE}

To study causative organisms and predisposing risk factors for sepsis in neonates. 


\section{MeTHODS}

This study is a hospital based prospective observational study, conducted during October 2017 to December 2018 in Department of Paediatric Medicine, SMS Medical College and attached group of hospitals, Jaipur. Neonates from birth to 28 days of life who were suspected neonatal septicemia were enrolled in the study. A sample size of 110 cases was covered. Detailed history and physical examination was done for all the patients. Blood samples from cases of neonatal septicemia were taken. The samples were processed in the Department of Microbiology to identify causative organism of suspected infection. For blood culture,
Brain Heart Infusion (BHI) broth in 1:10 dilution were inoculated and incubated at $37^{\circ} \mathrm{C}$ for $48 \mathrm{hrs}$. Any growth observed was subcultured on Blood Agar, Mckonkey's Agar and Sabroud's Dextrose Agar (SDA) with Chloramphenicol $(0.05 \%)$. Species of fungal infection were identified by Colony Morphology on SDA, Color on Chromogenic Media, Growth at $45^{\circ} \mathrm{C}$, Germ Tube test, Chlamydospore formation and Carbohydrate Fermentation. Neonates other than blood stream infection, seropositive mothers and refusal to give consent were not included in the study.

\section{RESULT}

Table-1: Neonatal and Maternal risk factors associated with Neonatal Sepsis

\begin{tabular}{|c|c|c|c|c|}
\hline \multirow{2}{*}{\multicolumn{2}{|c|}{ VARIABLES }} & \multicolumn{3}{|l|}{ NO OF CASES } \\
\hline & & BACTERIAL & FUNGAL & TOTAL \\
\hline \multirow[t]{6}{*}{ NEONATAL RISK FACTORS } & $>2$ Broad Spectrum Antibiotics & 24 & 5 & 29 \\
\hline & Prolonged Hospital Stay & 20 & 5 & 25 \\
\hline & Nil Orally $>5$ days & 21 & 5 & 26 \\
\hline & Central Line Insert & 22 & 5 & 27 \\
\hline & Mechanical Ventilation & 4 & 1 & 5 \\
\hline & Use of $\mathrm{H}_{2}$ Antagonist & 5 & 3 & 8 \\
\hline \multirow[t]{6}{*}{ PRENATAL RISK FACTORS } & Pregnancy induced hypertension & 3 & 1 & 4 \\
\hline & Bleeding & 2 & 1 & 3 \\
\hline & Antenatal Steroids & 12 & 3 & 15 \\
\hline & History of Fever & 18 & 4 & 22 \\
\hline & Foul Smell Discharge & 12 & 3 & 15 \\
\hline & Leaking Per Vaginal & 17 & 5 & 22 \\
\hline
\end{tabular}

Interpretation: Use of broad spectrum antibiotics and mechanical ventilation is most common neonatal risk factors leading to overall cases of neonatal sepsis. Use of antenatal steroids and fever with PV leaking is most common prenatal risk factors (Table-1).

Table-2: Factors affecting Neonatal Septicemia

\begin{tabular}{|c|c|c|c|c|c|c|}
\hline \multirow[t]{2}{*}{ VARIABLES } & & \multicolumn{3}{|l|}{ NO OF CASES } & \multirow{2}{*}{$\begin{array}{l}\text { TOTAL NO } \\
\text { OF CASES }\end{array}$} & \multirow[t]{2}{*}{ PERCENTAGE } \\
\hline & & BACTERIAL & FUNGAL & STERILE & & \\
\hline \multirow{2}{*}{$\begin{array}{l}\text { NEONATAL } \\
\text { SEX }\end{array}$} & MALE & & & & 65 & 59 \\
\hline & FEMALE & & & & 45 & 41 \\
\hline \multirow{4}{*}{$\begin{array}{l}\text { BIRTH } \\
\text { WEIGHT (Kg) }\end{array}$} & $<1.0 \mathrm{Kg}$ & 2 & 0 & 0 & 2 & 1.8 \\
\hline & $1.0-1.5 \mathrm{Kg}$ & 8 & 0 & 27 & 35 & 31.8 \\
\hline & $1.6-2.5 \mathrm{Kg}$ & 19 & 3 & 29 & 51 & 46.3 \\
\hline & $>2.5 \mathrm{Kg}$ & 4 & 1 & 17 & 22 & 20 \\
\hline \multirow{3}{*}{$\begin{array}{l}\text { GESTATIONAL } \\
\text { AGE (Weeks) }\end{array}$} & $\leq 32$ weeks & 15 & 2 & 25 & 42 & 38.1 \\
\hline & 33-36 weeks & 8 & 2 & 19 & 29 & 26.3 \\
\hline & $>37$ weeks & 9 & 1 & 29 & 39 & 35.4 \\
\hline \multirow[t]{2}{*}{ PARITY } & Primi & 10 & 5 & 50 & 75 & 68.1 \\
\hline & Multi & 21 & 1 & 23 & 35 & 31.8 \\
\hline
\end{tabular}

Interpretation: Premature birth, low birth weight and male newborns are most prone for neonatal septicemia so precautions and extra care must be done to prevent from septicemia (Table-2). 
Table-3: Clinical signs and symptoms presented by septicemic neonates.

\begin{tabular}{|l|c|c|}
\hline CLINICAL SIGN and SYMPTOMS of SEPTICEMIC NEONATES & NO OF CASES & PERCENTAGE \\
\hline Cyanosis & 4 & 3.6 \\
\hline Edema & 11 & 10 \\
\hline Perinatal Asphyxia & 23 & 20.9 \\
\hline Respiratory Distress & 60 & 54.5 \\
\hline Refusal to Feed & 97 & 88.1 \\
\hline Apnoea & 65 & 59.1 \\
\hline Neonatal convulsion & 17 & 15.4 \\
\hline Oliguria & 17 & 15.4 \\
\hline Hypothermia $\left(<35.4^{0} \mathrm{C}\right)$ & 47 & 42.7 \\
\hline Hyperthermia $\left(>37.5^{0} \mathrm{C}\right)$ & 53 & 48.1 \\
\hline Hypoglycemia $(<45 \mathrm{mg} \%)$ & 2 & 1.81 \\
\hline Shock (CRT $>3$ sec) & 17 & 15.4 \\
\hline Bleeding & 24 & 21.8 \\
\hline Jaundice & 18 & 16.3 \\
\hline Bulging Anterior Fontanelle & 54 & 49.1 \\
\hline
\end{tabular}

Interpretation: Most common clinical presentation in fungal septicemic neonates is feed refusal, apnoea, respiratory distress etc. Sign of meningeal involvement is bulging fontanelle (Table-3).

Table-4: Isolated causative organism causing Neonatal Septicemia

\begin{tabular}{|l|l|c|c|}
\hline & ISOLATED ORGANISM ON CULTURE & NO OF CASES & PERCENTAGE \\
\hline FUNGUS & CANDIDA & 5 & 4.54 \\
\hline \multirow{4}{*}{ BACTERIA } & ACINETOBACTER & 7 & 6.36 \\
\cline { 2 - 4 } & CITROBACTER & 1 & 0.90 \\
\cline { 2 - 4 } & CONS & 5 & 4.54 \\
\cline { 2 - 4 } & E.COLI & 3 & 2.72 \\
\cline { 2 - 4 } & KLEBSIELLA & 9 & 8.18 \\
\cline { 2 - 4 } & PSEUDOMONAS & 7 & 6.36 \\
\hline STERILE & 73 & 66.36 \\
\hline TOTAL & 110 & -- \\
\hline
\end{tabular}

\section{DISCUSSION}

Neonatal sepsis is the most common cause of neonatal mortality. Depending on the onset of symptoms, it can be classified into early onset sepsis, within $72 \mathrm{~h}$ of life and late onset sepsis, after $72 \mathrm{~h}$ of life. Mortality ranges from $30 \%$ to $70 \%$ among those infants who have early onset septicemia and is inversely related to the birth weight [4-7]. Risk factors for neonatal sepsis include an Apgar score 6 at 5 minutes, prolonged rupture of membranes, placental inflammation, and clinical amnionitis (maternal fever, fetal tachycardia, and amniotic or gastric fluid leukocytes or bacteria), prematurity and very low birth weight (VLBW), central vascular catheterization, parenteral nutrition, use of broad spectrum antibiotics, $\mathrm{H}_{2}$ blockers and corticosteroids, endotracheal intubation, and prolonged hospital stay [7]. Decreased gestational age and male sex have also been associated with an increased incidence of early neonatal sepsis [4, $5,8]$. Early signs of sepsis are frequently non-specific and subtle. It is difficult to clinically exclude sepsis in newborns less than 90 days old that have fever (defined as a temperature $>38^{\circ} \mathrm{C}\left(100.4^{\circ} \mathrm{F}\right)$. The overall incidence of neonatal sepsis has changed very little, as there has been a marked decrease in documented early onset sepsis, possibly due to the increased use of prenatal antibiotics [4]. The clinical features of early onset sepsis in babies of 34 weeks gestation are often indistinguishable from those of birth asphyxia or respiratory distress syndrome. More mature infants may present within 24 hours of birth with episodes of fever, respiratory distress, diarrhea, low blood sugar level, decreased movements, decreased suckling, seizures, bradycardia, swollen belly area, vomiting, jaundice or rash. A heart rate above 160 can also be an indicator of sepsis, this tachycardia can present up to 24 hours before the onset of other signs. The diagnosis can be made by Complete workup including complete blood count with differential, blood culture, urinalysis, urine culture, and cerebrospinal fluid (CSF) studies and CSF culture, admit the newborn to the hospital, and treat empirically for serious bacterial infection for at least 48 hours until cultures are demonstrated to show no growth. Culturing for microorganisms from a sample of CSF, blood or urine, is the gold standard test for definitive diagnosis of neonatal sepsis. This can give false negatives due to the low sensitivity of culture methods and because of concomitant antibiotic therapy. This is particularly challenging in cases in which intrapartum maternal antibiotic therapy has been administered, which may affect the ability to detect organisms in the neonatal blood cultures. Lumbar punctures should be done when possible as $10-15 \%$ presenting with sepsis also have meningitis, which warrants an antibiotic with a high CSF penetration. CRP is not very accurate in picking up cases of neonatal sepsis [9]. In neonates, sepsis is difficult to diagnose 
clinically. Neonates remain relatively asymptomatic until hemodynamic and respiratory collapse is imminent, so, if there is suspicion of sepsis, they are frequently treated with antibiotics empirically until cultures are sufficiently proven to be negative. In addition to fluid resuscitation and supportive care, a common antibiotic regimen in infants with suspected sepsis is a beta-lactam antibiotic (usually ampicillin) in combination

with an aminoglycoside (usually gentamicin) or a third generation cephalosporin ( usually cefotaxime ceftriaxone is generally avoided in neonates due to the theoretical risk of kernicterus). The organisms which are targeted are species that predominate in the female genitourinary tract and to which neonates are especially vulnerable to, specifically Group B Streptococcus, Escherichia coli and Listeria monocytogenes (This is the main rationale for using ampicillin versus other beta-lactams.) Of course, neonates are also vulnerable to other common pathogens that can cause meningitis and bacteremia such as Streptococcus pneumoniae and Neisseria meningitidis. Although uncommon, if anaerobic species are suspected (such as in cases where necrotizing enterocolitis or intestinal perforation is a concern, clindamycin is often added. Granulocyte-macrophage colony stimulating factor (GM-CSF) is sometimes used in neonatal sepsis. However, a 2009 study found that GM-CSF corrects neutropenia if present but it has no effect on reducing sepsis or improving survival [10].

\section{SumamRY AND CONCLUSION}

Neonatal sepsis is associated with significant morbidity and mortality. Blood culture, although not a sensitive test, remains the only reliable method for diagnosis. This study indicated that the prevalence of neonatal sepsis was high. Although, this study also tells that several factors like maternal age, multiple per vaginal examination, exclusive and immediate breastfeeding within an hour of delivery, put on Kangaroo Mother care (KMC) within 1 hour, and age of the neonate are the factors affecting or predisposing neonates for sepsis. Mechanical ventilation > 5 Days, central line $>7$ Days, $20 \%$ intra lipid infusion $>7$ Days, use of $>2$ broad spectrum antibiotics, prolonged stay in hospital $>7$ days and thrombocytopenia were the most common risk factors. Based on this study we recommend strengthening of provision of health information on exclusive and immediate breastfeeding and $\mathrm{KMC}$ for mothers during postnatal and antenatal care services. Using Information Education Communication / Behavior Change Communication materials (posters, flip charts, wall paintings, manuals, brushers, and pamphlets) focused on breastfeeding and KMC to mobilize and sensitize the community. In addition, it should be recommended that the healthcare providers decrease multiple per digital vaginal examination as it is not indicated but better to be promoted. Prevention of risk factors in susceptible neonates with early removal of central line, timely blood culture, causative species identification and susceptibility testing are necessary for appropriate institution of treatment and better outcome. Frequent antibiotic use should be avoided as it may lead to a shift in species distribution and higher pathogenic resistance.

\section{REFERENCES}

1. Edwards MS. Postnatal infections. In: Martin RJ, Fanaroff AA, Walsh MC, editors. NeonatalPerinatal Medicine. 8thed. Philadelphia: Mosby Elsevier; 2006. p.791-804.

2. Galhotra S, Gupta V, Bains HS, Chhina D. Clinico-bacteriological profile of neonatal septicemia in a tertiary care hospital. J Mahatma Gandhi Inst Med Sci. 2015; 20:148-52.

3. Pandita N, Peshin C, Wasim S, Bhat NK, Gupta A. Profile of fungal septicaemia in new born at a tertiary care hospital in North India. Int J Contemp Pediatr. 2017; 4:455-9.

4. Freedman R, Ingram DL, Gross I, Ehrenkranz RA, Warshaw JB, Baltimore RS. A half century of neonatal sepsis at Yale: 1928 to 1978 . Am J Dis Child. 1981; 135:140-4.

5. Philip AGS. The changing face of neonatal infection: experience at a regional medical center. Pediatr Infect Dis J. 1994; 13:1098-102.

6. Placzek M, Whitelaw A. Early and late neonatal septicemia. Arch Dis Child. 1983; 58:728-31.

7. Geme Jr JW, Murray DL, Carter J, Hobel CJ, Leake RD, Anthony BF, Thibeault DC, Ross IB, Drage JS. Perinatal bacterial infection after prolonged rupture of amniotic membranes: an analysis of risk and management. The Journal of pediatrics. 1984 Apr 1;104(4):608-13.

8. Stoll BJ, Gordon T, Korones SB, Shankaran S, Tyson JE, Bauer CR, Fanaroff AA, Lemons JA, Donovan EF, Oh W, Stevenson DK. Early-onset sepsis in very low birth weight neonates: a report from the National Institute of Child Health and Human Development Neonatal Research Network. The Journal of pediatrics. 1996 Jul 1;129(1):72-80.

9. Delanghe JR, Speeckaert MM. Translational research and biomarkers in neonatal sepsis. Clinica Chimica Acta. 2015 February; 451: 46-64.

10. Carr R, Brocklehurst P, Doré CJ, Modi N. Granulocyte-macrophage colony stimulating factor administered as prophylaxis for reduction of sepsis in extremely preterm, small for gestational age neonates (the PROGRAMS trial): a single-blind, multicentre, randomised controlled trial. Lancet. 2009 January; 373(9659): 226-33. 